\title{
Asthma and youth soccer: an investigation into the level of asthma awareness and training among youth soccer coaches
}

This article was published in the following Dove Press journal:

Open Access Journal of Sports Medicine

\author{
Chandu Sadasivan \\ Andrew Cave \\ Department of Family Medicine, \\ University of Alberta, Edmonton, AB, \\ Canada
}

Purpose: Asthma is the most common chronic disease among children. Exercise-induced bronchoconstriction which is common in asthmatic patients also occurs in individuals with no prior asthma diagnosis. Despite this and the fact that soccer is a high ventilation sport, there are no validated asthma management protocols in place for soccer coaches. This study aims to address 1) soccer coaches' current knowledge on asthma, 2) whether there is a need for asthmarelated training, and 3) any barriers to administration of such training.

Patients and methods: A total of 2,300 volunteer youth soccer coaches from the Edmonton Minor Soccer Association (EMSA) were invited to participate in completing a 22-question online survey. The survey was open for 1 month from June 8, 2018, to July 8, 2018.

Results: There was a response rate of $22 \%$ (513 of 2,300). Respondents were on average, inexperienced coaches, coached younger age groups, and approximately one-third of respondents had personal experience with asthma (either themselves or their child had asthma). 93\% of respondents had not received any asthma-related training at any coaching level, whether it be from EMSA or the Alberta Soccer Association. Coaches had strong knowledge on how to treat asthma attacks, but mixed levels of knowledge on asthma attack prevention. Experienced coaches were better at identifying the number of players with asthma on their team and the number of asthma-related incidents they had encountered as coaches. Coaches demonstrated a receptive attitude toward receiving asthma-related training, with $91 \%$ of respondents saying training would be beneficial and $69 \%$ of respondents saying training should be mandatory.

Conclusion: The results of this study indicate that soccer coaches have limited knowledge regarding asthma management, acknowledge a need for asthma-related training, and are willing to participate in and could benefit from educational interventions as it pertains to their roles as coaches.

Keywords: coaching, exercise-induced bronchoconstriction, management, protocol

\section{Introduction}

Asthma is an obstructive pulmonary disorder affecting hundreds of millions of people around the world. ${ }^{1,2}$ The disorder is distinguished by coughing, shortness of breath, chest tightness, and wheezing. Epidemiological studies have noted that asthma is the most common chronic disease among children, yet, the burden of asthma is often overlooked, because deaths are more common from other respiratory conditions such as tuberculosis and pneumonia. ${ }^{3}$ It is important to note that exercise-induced bronchoconstriction (EIB) or narrowing of the airway that occurs in association with exercise occurs in up to $90 \%$ of asthmatic patients and also over $10 \%$ of the general
Correspondence: Chandu Sadasivan

University of Alberta, 6-10 University

Terrace, Edmonton, AB T6G 2T4,

Canada

Tel + I 7804928102

Fax +I 7804922593

Email sadasiva@ualberta.ca 
population with no previous asthma diagnosis. ${ }^{4,5}$ Additionally, the prevalence of EIB varies according to the sport being played, with high ventilation sports such as soccer, crosscountry running, and ice hockey having higher rates of EIB. ${ }^{4}$ The prevalence of EIB also varies depending on the presence of certain environmental pollutants, such as chlorine, carbon monoxide, nitrogen dioxide, and pollen. ${ }^{4,6}$

Asthma often serves as a barrier for children from participating in physical activity, which can lead to issues such as negative social well-being and overall poor quality of life for these children. ${ }^{78}$ Although results are not fully conclusive, some studies have found that lower levels of physical activity can then further exacerbate their existing asthma conditions. ${ }^{9}$ Furthermore, it was found that between 1993 and 2000, there were 61 sports-related deaths in the United States as a result of asthma, with most of the deaths in athletes under the age of 20 years..$^{10}$ Soccer has become the sport of choice for many youth around the world and is often described as the most popular sport around the world. ${ }^{11}$ Since soccer requires continuous activity, it is one of the sports that makes people most susceptible to an asthma attack. ${ }^{12}$ Despite these statistics and the associated risk between asthma and soccer, we could find no specific and validated protocols in place for coaches dealing with asthma in a soccer setting, although an exploratory study evaluating an online module educating soccer coaches on air quality and respiratory health for soccer coaches was recently published. ${ }^{13}$

There could be a multitude of reasons contributing to this lack of protocol, such as soccer coaches' rare encounters with asthma, the possibility that current protocol may be outdated, or barriers to administration of such protocol either from league administrators or coaches themselves. With millions of youth soccer coaches across the world, these individuals could assist in the early recognition of asthmatic symptoms and help improve the functioning of asthmatic soccer players. Therefore, we felt it was necessary to investigate 1) youth soccer coach awareness about asthma and the current level of asthma-related training offered to soccer coaches, 2) whether there is a need for asthma-related training for coaches, and 3) if there are any barriers to administration of such training by assessing coaches' attitudes regarding asthma. This is the second study looking at asthma knowledge specifically in a soccer setting, but the previous study was limited by a small sample size, it also did not look specifically at coaches' knowledge, and the authors called for further studies to identify potential ways to address the lack of knowledge and identification of asthmatic players in youth soccer. ${ }^{14}$ This study aims to meet those needs. We hypothesize that 1) soccer coaches will have low levels of knowledge regarding asthma attack prevention/treatment and have received little to no asthma-related training, 2) there is a need for asthma-related training, and 3) there will be some barriers to administration of asthma training due to coaches' negative attitude regarding asthma.

\section{Methods}

Volunteer youth soccer coaches from the Edmonton Minor Soccer Association (EMSA) were invited to participate in this study. EMSA has teams comprising over 25,000 youth throughout Edmonton and the surrounding areas. ${ }^{25}$ Teams have an age range from under 5 to under 19. An online survey was sent to the coaches halfway through the outdoor soccer season in June 2018 (Table 1). The survey was constructed with 22 questions, with an aim to assess 1) demographics (questions $1-5), 2$ ) coaches' asthma awareness and knowledge (questions 6-9), 3) whether there is a need for asthma-related training (questions 10-14), and 4) barriers to administration of asthma training (questions 15-22). Certain questions were selected from a previous study assessing coach and manager knowledge about asthma. ${ }^{14}$ We worked in collaboration with the EMSA throughout the course of this study. They had access to the electronic mailing addresses of all currently active coaches for the 2018 outdoor soccer season. The survey was sent out electronically using SurveyMonkey, which is an online survey development software. ${ }^{15}$ The survey questions and methodology of administration were approved by the University of Alberta Research Ethics Board. Participants were assured anonymity prior to completing the survey and informed consent was implied by completion of the survey. The survey was electronically mailed out to 2,300 volunteer soccer coaches in Edmonton and surrounding areas. There were 513 coaches who completed the survey, meaning the response rate was $22.3 \%$. Despite this response rate, a number of respondents had not fully completed the survey. There were only 442 coaches who completed the survey in full. We performed descriptive statistical analysis after filtering responses by completeness. SurveyMonkey filtered out the responses where respondents did not reach the end of the survey, respondents who did not answer all questions but finished the survey were still included as part of our descriptive analysis. Chi-squared tests were also performed to compare the responses to different questions filtered by responses to other questions on the survey. Comparisons were made between responses to questions 1, 2, 3, 4, 5, 11, and 13 against responses to questions 7 through 22 to determine if any statistically significant differences existed in the responses (Table 2). These questions were chosen for 
Table I Survey instrument

\begin{tabular}{|c|c|}
\hline \multirow[t]{8}{*}{ I. What age level do you currently coach? Select all that apply. } & I. U5 \\
\hline & 2. U7 \\
\hline & 3. U9 \\
\hline & 4. UII \\
\hline & 5. UI3 \\
\hline & 6. UI5 \\
\hline & 7. UI7 \\
\hline & 8. U19 \\
\hline \multirow[t]{3}{*}{ 2. What gender do you coach? } & I. Boys \\
\hline & 2. Girls \\
\hline & 3. Mixed or both \\
\hline \multirow[t]{4}{*}{ 3. How many seasons have you coached for? } & I. I-2 \\
\hline & 2. $3-4$ \\
\hline & 3. 5-6 \\
\hline & 4. $7+$ \\
\hline \multirow[t]{2}{*}{ 4. Do you or your child have asthma? } & I. Yes \\
\hline & 2. No \\
\hline \multirow[t]{3}{*}{ 5. What is your current level of coach training/certification? } & I. None \\
\hline & 2. Certified by EMSA \\
\hline & 3. Training by Alberta Soccer Association (ASA/NCCP courses) \\
\hline \multirow{3}{*}{$\begin{array}{l}\text { 6. At which coaching certification level did you receive asthma-related } \\
\text { training? Select all that apply. }\end{array}$} & I. None \\
\hline & 2. Certification by EMSA \\
\hline & 3. Training by ASA \\
\hline \multirow[t]{5}{*}{ 7. What is the best way to prevent asthma attacks? } & I. Inhaler when first short of breath \\
\hline & 2. Inhaler when very short of breath \\
\hline & 3. Inhaler before exercise \\
\hline & 4. Warm-up exercises \\
\hline & 5. Other (not sure) \\
\hline \multirow[t]{4}{*}{ 8. How do you treat an asthma attack? } & I. Give quick-relief inhaler \\
\hline & 2. Lift arms above head \\
\hline & 3. Breathe into a paper bag \\
\hline & 4. Other (do not know) \\
\hline \multirow{4}{*}{$\begin{array}{l}\text { 9. When you notice an asthmatic player seems short of breath, what } \\
\text { usually happens? }\end{array}$} & I. Wait for the player to indicate that he or she needs to go out \\
\hline & 2. Pull him or her out of the game immediately \\
\hline & 3. Wait for the parent to indicate that he or she needs to go out \\
\hline & 4. Other \\
\hline \multirow[t]{4}{*}{ 10. How many players on your current team have asthma? } & I. Not sure \\
\hline & 2. $1-2$ \\
\hline & 3. 3-4 \\
\hline & 4. $5+$ \\
\hline \multirow{4}{*}{$\begin{array}{l}\text { II. How many asthma-related incidents have you encountered as a } \\
\text { coach? }\end{array}$} & I. Not sure \\
\hline & 2. $1-2$ \\
\hline & 3. $3-4$ \\
\hline & $4.5+$ \\
\hline \multirow{5}{*}{$\begin{array}{l}\text { 12. How often do you discuss with parents/players a plan to follow if the } \\
\text { player has an asthma attack? }\end{array}$} & I. Never \\
\hline & 2. Rarely \\
\hline & 3. Sometimes \\
\hline & 4. Most of the time \\
\hline & 5. Always \\
\hline \multirow[t]{4}{*}{ 13. I know how to treat a player who is having an asthma attack. } & I. Strong disagree \\
\hline & 2. Disagree \\
\hline & 3. Agree \\
\hline & 4. Strongly agree \\
\hline \multirow{4}{*}{$\begin{array}{l}\text { 14. Asthma management is the responsibility of the player/parent and not } \\
\text { the responsibility of the coach. }\end{array}$} & I. Strongly disagree \\
\hline & 2. Disagree \\
\hline & 3. Agree \\
\hline & 4. Strongly agree \\
\hline
\end{tabular}


Table I (Continued)

\begin{tabular}{|c|c|}
\hline \multirow{2}{*}{$\begin{array}{l}\text { 15. Do you think incorporation of asthma management protocol into } \\
\text { coach training would be beneficial? }\end{array}$} & I. Yes \\
\hline & 2. No \\
\hline \multirow{4}{*}{$\begin{array}{l}\text { 16. What would be the best way to incorporate asthma-related protocol } \\
\text { into coach training? }\end{array}$} & I. Pocket guide (similar to current concussion protocol) \\
\hline & 2. Online module \\
\hline & 3. Include short segment into current EMSA training \\
\hline & 4. Separate I hour asthma training course \\
\hline \multirow{2}{*}{$\begin{array}{l}\text { 17. Should training in asthma management be mandatory for all EMSA } \\
\text { coaches? }\end{array}$} & I. Yes \\
\hline & 2. No \\
\hline \multirow{2}{*}{$\begin{array}{l}\text { 18. Would you be interested in asthma training if it were developed by } \\
\text { EMSA? }\end{array}$} & I. Yes \\
\hline & 2. No \\
\hline \multirow[t]{4}{*}{ 19. Asthma is adequately covered in current coaching courses. } & I. Strongly disagree \\
\hline & 2. Disagree \\
\hline & 3. Agree \\
\hline & 4. Strongly agree \\
\hline \multirow[t]{4}{*}{ 20. Asthma does not affect many children. } & I. Strongly disagree \\
\hline & 2. Disagree \\
\hline & 3. Agree \\
\hline & 4. Strongly agree \\
\hline \multirow[t]{4}{*}{21. Asthma is already appropriately managed by parents and physicians. } & I. Strongly disagree \\
\hline & 2. Disagree \\
\hline & 3. Agree \\
\hline & 4. Strongly agree \\
\hline \multirow[t]{4}{*}{ 22. Coaches have adequate knowledge in asthma management. } & I. Strongly disagree \\
\hline & 2. Disagree \\
\hline & 3. Agree \\
\hline & 4. Strongly agree \\
\hline
\end{tabular}

Abbreviations: ASA, Alberta Soccer Association; EMSA, Edmonton Minor Soccer Association.

analysis based on clinical and coaching experience of the researchers and EMSA collaborators. Figures depicting significant relationships between respondents' answers on different questions were selected and have been outlined in the Results section. These figures were chosen based on trends seen in the data, which would assist us to draw appropriate conclusions on our given sample.

\section{Results}

\section{Respondent demographics}

The majority of respondents $(>80 \%, 355$ coaches) coached in the under 5 to under 11 age group (Table 3 ). The mean age group coached with rounding was U11. In terms of experience, inferred through number of seasons coached, $45 \%$ of the coaches had only coached for 1-2 seasons, but the mean number of seasons coached with rounding was 3-4 seasons. Additionally, one-third of the coaches answered "yes" to whether they or their child have asthma. The majority of the coaches had some form of training (58.22\%) in coaching, but not in asthma care.

\section{Coaches' asthma awareness and knowledge}

Of the coaches who responded, 93\% said that they had never received asthma-related training at any coaching certification
Table 2 Chi-square values/P-values for all relevant statistically significant cross tabulations completed

\begin{tabular}{|c|c|c|}
\hline & $\begin{array}{l}\text { Chi-square } \\
\text { value }\end{array}$ & $\begin{array}{l}\text { Asymptotic } \\
\text { significance } \\
\text { (two-tailed) }\end{array}$ \\
\hline Question $3 \times$ Question 7 & 33.833 & 0.001 \\
\hline Question $3 \times$ Question 10 & 38.054 & $<0.001$ \\
\hline Question $3 \times$ Question II & 107.553 & $<0.001$ \\
\hline Question $3 \times$ Question 12 & 79.117 & $<0.001$ \\
\hline Question $3 \times$ Question 16 & 36.197 & $<0.001$ \\
\hline Question $4 \times$ Question 7 & 35.702 & $<0.001$ \\
\hline Question $4 \times$ Question 8 & 17.959 & $<0.001$ \\
\hline Question $4 \times$ Question 10 & 24.010 & $<0.001$ \\
\hline Question 4× Question II & 9.675 & 0.022 \\
\hline Question $4 \times$ Question 13 & 39.446 & 0.000 \\
\hline Question II $\times$ Question 7 & 44.646 & $<0.001$ \\
\hline Question II $\times$ Question 8 & 20.197 & 0.017 \\
\hline Question II × Question 12 & 171.838 & $<0.001$ \\
\hline Question $13 \times$ Question 7 & 76.716 & $<0.001$ \\
\hline Question $13 \times$ Question 8 & 91.222 & $<0.001$ \\
\hline
\end{tabular}

Note: The multiplication sign indicates a comparison of the responses between the two questions listed.

level (Table 4). The majority of coaches knew how to treat an asthma attack by giving a quick-relief inhaler and what to do with an asthmatic player who was out of breath while on the field. There were far fewer coaches who knew how to prevent an asthma attack by providing an inhaler before exercise. 
Table 3 Respondent demographics

\begin{tabular}{|c|c|c|c|}
\hline Questions & Levels & No. of subjects & $\%$ of subjects \\
\hline \multirow[t]{8}{*}{ What age level do you currently coach? } & U5 & 87 & 19.73 \\
\hline & U7 & 95 & 21.54 \\
\hline & U9 & 83 & 18.82 \\
\hline & UII & 90 & 20.41 \\
\hline & UI3 & 52 & 11.79 \\
\hline & UI5 & 59 & 13.38 \\
\hline & UI7 & 27 & 6.12 \\
\hline & U19 & 13 & 2.95 \\
\hline \multirow[t]{3}{*}{ What gender do you coach? } & Boys & 168 & 38.10 \\
\hline & Girls & 118 & 26.76 \\
\hline & Mixed or both & 155 & 35.15 \\
\hline \multirow[t]{4}{*}{ How many seasons have you coached for? } & $\mathrm{I}-2$ & 201 & 45.48 \\
\hline & $3-4$ & 95 & 21.49 \\
\hline & $5-6$ & 57 & 12.90 \\
\hline & $7+$ & 89 & 20.14 \\
\hline \multirow[t]{2}{*}{ Do you or your child have asthma? } & Yes & 147 & 33.26 \\
\hline & No & 295 & 66.74 \\
\hline \multirow{3}{*}{$\begin{array}{l}\text { What is your current level of coach training/ } \\
\text { certification? }\end{array}$} & None & 183 & 41.78 \\
\hline & Certification by EMSA & 138 & 31.51 \\
\hline & Training by ASA & 117 & 26.71 \\
\hline
\end{tabular}

Abbreviations: ASA, Alberta Soccer Association; EMSA, Edmonton Minor Soccer Association.

Table 4 Coaches' asthma awareness and knowledge

\begin{tabular}{|c|c|c|c|}
\hline Questions & Levels & No. of subjects & $\%$ of subjects \\
\hline \multirow{3}{*}{$\begin{array}{l}\text { At which training level did you } \\
\text { receive asthma-related training? } \\
\text { Select all that apply. }\end{array}$} & None & 410 & 93.18 \\
\hline & Certification by EMSA & 19 & 4.32 \\
\hline & Training by ASA & 13 & 2.95 \\
\hline \multirow{5}{*}{$\begin{array}{l}\text { What is the best way to prevent an } \\
\text { asthma attack? }\end{array}$} & Inhaler when first short of breath & 118 & 26.94 \\
\hline & Inhaler when very short of breath & 8 & 1.83 \\
\hline & *Inhaler before exercise & 169 & 38.58 \\
\hline & Warm-up exercises & 42 & 9.59 \\
\hline & Other (not sure) & 101 & 23.06 \\
\hline \multirow[t]{4}{*}{ How do you treat an asthma attack? } & *Give quick-relief inhaler & 356 & 80.73 \\
\hline & Lift arms above head & 23 & 5.22 \\
\hline & Breathe into a paper bag & 5 & 1.13 \\
\hline & Other (don't know) & 57 & 12.93 \\
\hline \multirow{4}{*}{$\begin{array}{l}\text { When you notice an asthmatic player } \\
\text { seems short of breath, what usually } \\
\text { happens? }\end{array}$} & Wait for the player to indicate that he or she needs to go out & 62 & 14.06 \\
\hline & *Pull him or her out of the game immediately & 342 & 77.55 \\
\hline & Wait for the parent to indicate that he or she needs to go out & 8 & 1.81 \\
\hline & Other & 29 & 6.58 \\
\hline
\end{tabular}

Note: *Indicates correct response.

Abbreviations: ASA, Alberta Soccer Association; EMSA, Edmonton Minor Soccer Association.

We filtered coaches' responses to these asthma knowledge questions by the age level that they coached. There were no significant trends seen in the responses to how to treat an asthma attack or how to deal with an asthmatic player suffering an asthmatic attack, as coaches across all age levels answered consistently. However, it can be seen that coaches' knowledge regarding asthma attack prevention seems to increase by the age level being coached, with U19 coaches having the greatest percentage of respondents knowing the correct response (Figure 1). It is also important to note that $\mathrm{U} 5$ and $\mathrm{U} 7$ coaches were split between three responses: "other (not sure)," "inhaler when first short of breath," and "inhaler before exercise."

We also looked at the responses to these asthma knowledge questions in relation to the number of seasons coached. 
There were no significant differences in responses to the question regarding how to treat an asthma attack. It was seen that there was a linear correlation between responses to the asthma attack prevention question and number of seasons coached, with more experienced coaches having better knowledge on asthma attack prevention (Figure 2).

We then filtered the responses to these knowledge questions by the level of asthma experience that these coaches had based on their responses to whether they or their child had asthma and the number of asthma-related incidents they had encountered as a coach. Among coaches who answered "yes" to the question of whether they or their child had asthma, there was a significantly higher proportion of coaches who knew the correct response to the asthma attack treatment and prevention questions compared to the coaches who had answered "no" $(P<0.05)$. There were no significant differences in their responses to the question regarding what to do with an asthmatic player out of breath. Coaches who had encountered more asthma-related incidents knew the correct response to asthma attack prevention/treatment questions

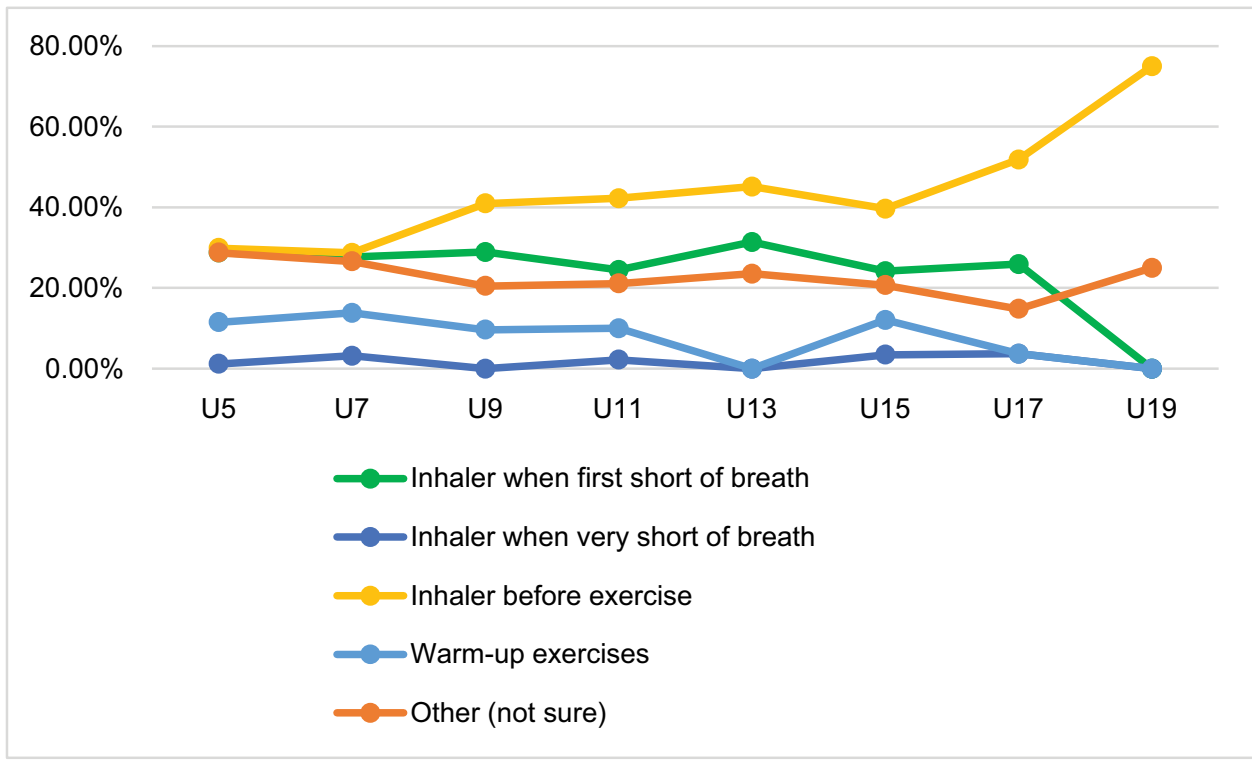

Figure I Responses to asthma attack prevention question filtered by age level coached.

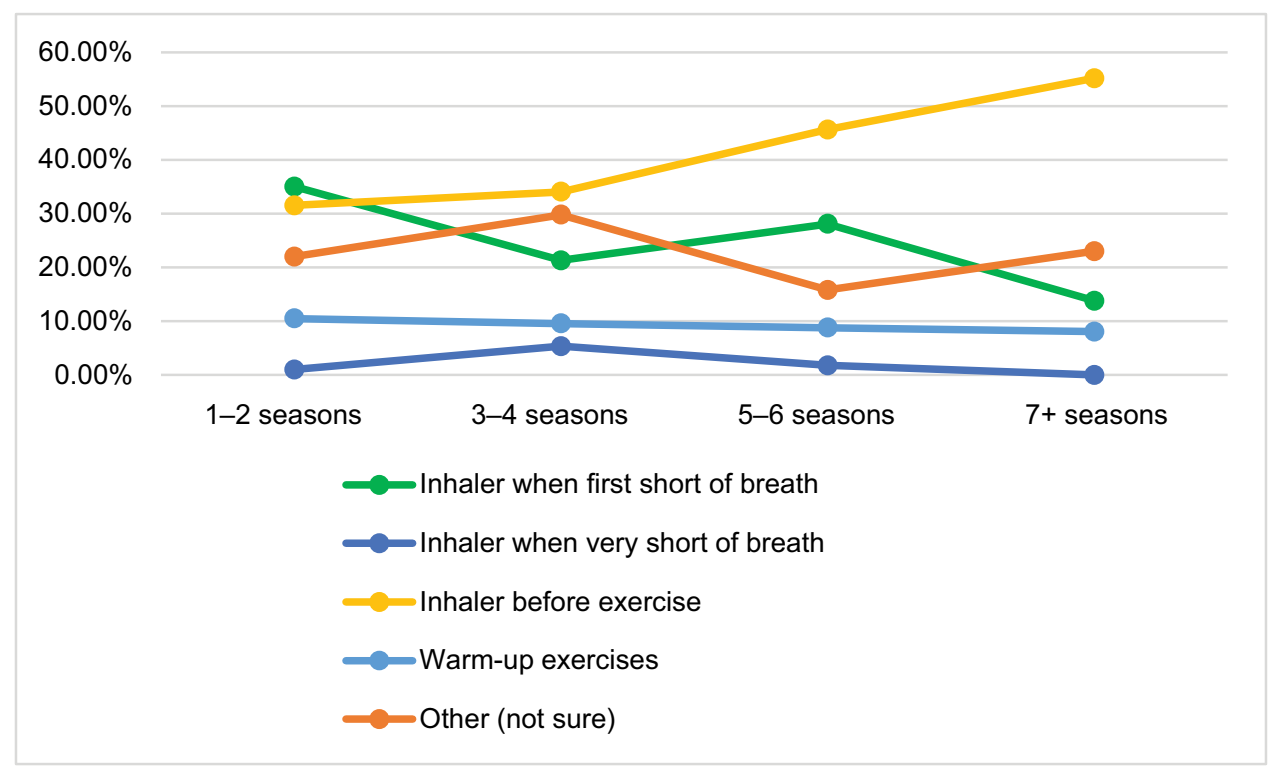

Figure 2 Responses to asthma attack prevention question filtered by number of seasons coached. 
compared to the coaches who were "not sure" how many asthma-related incidents they had encountered $(P<0.05)$.

We also filtered these asthma knowledge questions by the confidence levels that coaches had as indicated by their response to Question 13: "I know how to treat a player who is having an asthma attack." For these asthma knowledge questions, coaches with greater confidence levels (agree or disagree with Q13) had significantly greater knowledge in preventing an asthma attack and coping with an asthmatic player who was short of breath $(P<0.05)$. Coaches with greater confidence level (strongly agree or agree) also had greater knowledge in how to treat an asthma attack (Figure 3).

We also filtered the responses to these asthma knowledge questions by gender being coached and the level of training received (EMSA or ASA), but there were no significant differences noted.

\section{Need for asthma-related training}

Of the coaches who responded, $51 \%$ and $59 \%$ of them said that they were not sure how many players on their current team have asthma or how many asthma-related incidents they had encountered as a coach, respectively (Table 5). The majority of coaches (59\%) never discuss with parents a plan to follow if a player has an asthma attack, while $7 \%$ of coaches always discuss a plan to follow. Overall, a majority of the coaches $(52 \%)$ said they knew how to treat a player who is having an asthma attack (answered agree or strongly agree to the question on how to treat a player who is having an asthma attack). Nearly three quarters $(72 \%)$ of the coaches disagreed or strongly disagreed with the statement that asthma management is the responsibility of the player/ parent and not the responsibility of the coach.

We then filtered the responses to these questions by age level coached. It appears that on average, recognition of the number of players with asthma and the number of asthmarelated incidents recalled increase by age level being coached and the number of coaches "not sure" tends to drop as we increase the age level being coached (Figure 4).

We then compared the responses to these frequency questions by the experience level of coaches as indicated by the number of seasons coached for. It appears that on average, the number of players with asthma and the number of asthma-related incidents is positively correlated with the level of experience of the coach and the number of coaches "not sure" tends to drop as experience increases. This is similar to the trend seen by the age level being coached. The number of coaches' never discussing an action plan tends to decrease with experience (Figure 5). There were no significant differences in confidence levels by experience.

We then filtered the responses to these need-related questions by the level of asthma experience that these coaches had based on their responses to whether they or their child had asthma. Among coaches who answered "yes" to the question of whether they or their child had asthma, there were a significantly higher proportion of coaches who identified either 1-2 or 3-4 players on their team having asthma $(P<0.05$, Figure 6$)$. This could be an indication of bias in the sample. There were no significant differences

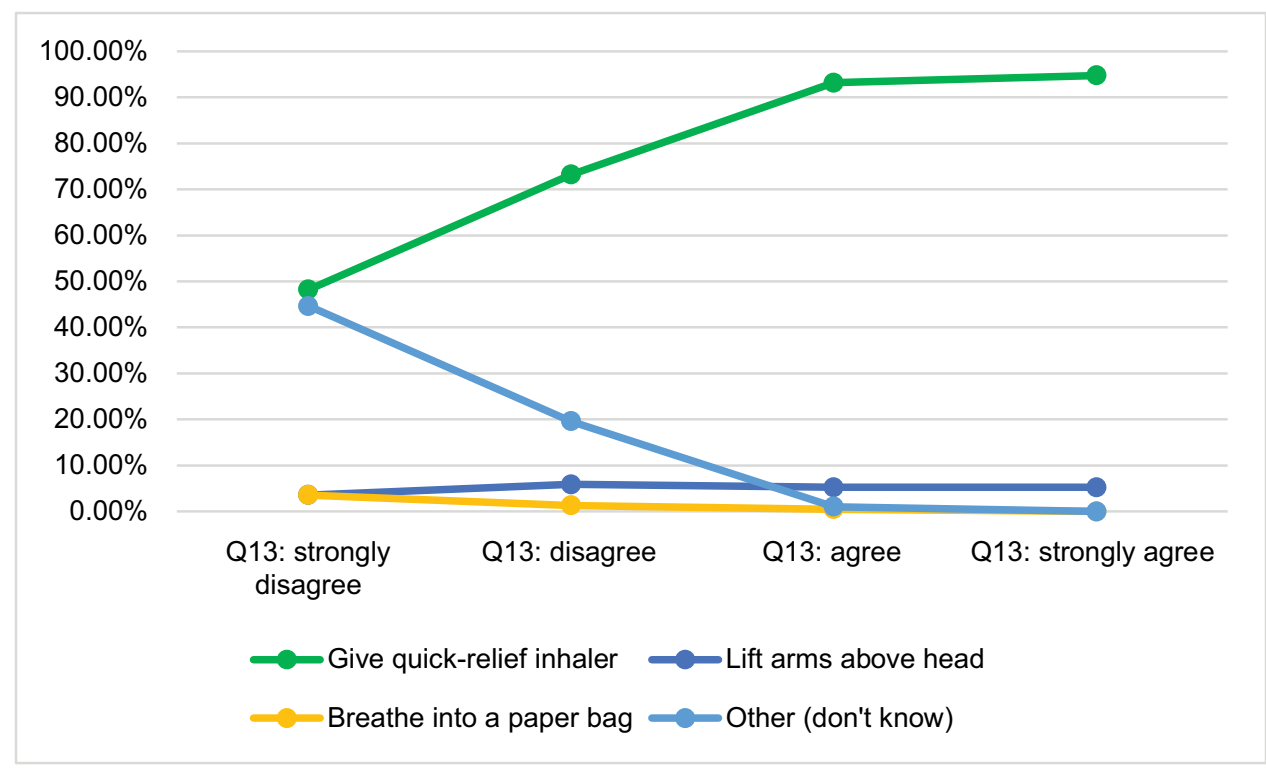

Figure 3 Responses to asthma attack treatment question filtered by confidence levels. 
Table 5 Need for asthma-related training

\begin{tabular}{|c|c|c|c|}
\hline Questions & Levels & $\begin{array}{l}\text { No. of } \\
\text { subjects }\end{array}$ & $\%$ of subjects \\
\hline \multirow[t]{4}{*}{ How many players on your current team have asthma? } & Not sure & 223 & 51.15 \\
\hline & $\mathrm{I}-2$ & 177 & 40.60 \\
\hline & $3-4$ & 34 & 7.80 \\
\hline & $5+$ & 2 & 0.46 \\
\hline \multirow[t]{4}{*}{ How many asthma-related incidents have you encountered as a coach? } & Not sure & 254 & 58.93 \\
\hline & $\mathrm{I}-2$ & 142 & 32.95 \\
\hline & $3-4$ & 16 & 3.71 \\
\hline & $5+$ & 19 & 4.41 \\
\hline \multirow{5}{*}{$\begin{array}{l}\text { How often do you discuss with parents/players a plan to follow if the } \\
\text { player has an asthma attack? }\end{array}$} & Never & 256 & 58.58 \\
\hline & Rarely & 89 & 20.37 \\
\hline & Sometimes & 49 & 11.21 \\
\hline & Most of the time & 13 & 2.97 \\
\hline & Always & 30 & 6.86 \\
\hline \multirow[t]{4}{*}{ I know how to treat a player who is having an asthma attack. } & Strongly disagree & 56 & 12.79 \\
\hline & Disagree & 154 & 35.16 \\
\hline & Agree & 190 & 43.38 \\
\hline & Strongly agree & 38 & 8.68 \\
\hline \multirow{4}{*}{$\begin{array}{l}\text { Asthma management is the responsibility of the player/parent and not } \\
\text { the responsibility of the coach. }\end{array}$} & Strongly disagree & 84 & 19.09 \\
\hline & Disagree & 232 & 52.73 \\
\hline & Agree & 114 & 25.91 \\
\hline & Strongly agree & 10 & 2.27 \\
\hline
\end{tabular}

in responses to the question regarding number of asthmarelated incidents or how often coaches discussed asthma action plans. Coaches who had personal asthma experience had significantly higher confidence in treating a player with an asthma attack $(P<0.05)$. There was no statistical difference between respondents who had asthma experience vs those who did not with the statement that asthma management is the responsibility of the player/parent and not the responsibility of the coach. As the number of asthma-related incidents encountered increased, coaches were significantly more likely to discuss an action plan if a player has an asthma attack (Figure 7).

We also filtered the responses to these need-related questions by gender being coached, level of training received (EMSA or ASA), and by confidence levels, but there were no significant differences noted.

\section{Barriers to administration of training}

Of the coaches who responded, the majority of them felt that incorporation of asthma management protocol into coach training would be beneficial, that training in asthma management should be mandatory for all EMSA coaches, and that they would be interested in asthma training if it were to be developed by EMSA (Table 6). In terms of the best way to incorporate asthma-related protocol into coach training, most coaches felt a pocket guide would be most suitable.
However, there was also a large portion of coaches in favor of including a short segment into current EMSA training. Very few coaches wanted a separate 1 hour asthma training course. The majority of coaches disagreed with the statements "asthma is adequately covered in current coaching courses," "asthma does not affect many children," and "youth soccer coaches have adequate knowledge in asthma management." At the same time, the majority of coaches agreed with the statement that "asthma is already appropriately managed by parents and physicians."

We filtered the responses to these barriers questions by the age level that they coached. No significant differences were noted, except for the question regarding the best way to incorporate asthma-related protocol into coach training. As the age level being coached increased, coaches were more in favor of a pocket guide, while coaches at lower age levels were more in favor of inclusion of a short segment into coach training (Figure 8).

We also compared responses to these barrier questions in terms of experience of the coaches, which was inferred by the number of seasons that they coached for. It was noted that more experienced coaches felt that a pocket guide would be the best way to administer asthma-related training, whereas less experienced coaches felt that inclusion of a short segment into current training would be the best way. It was also noted that more experienced coaches were the most likely to 

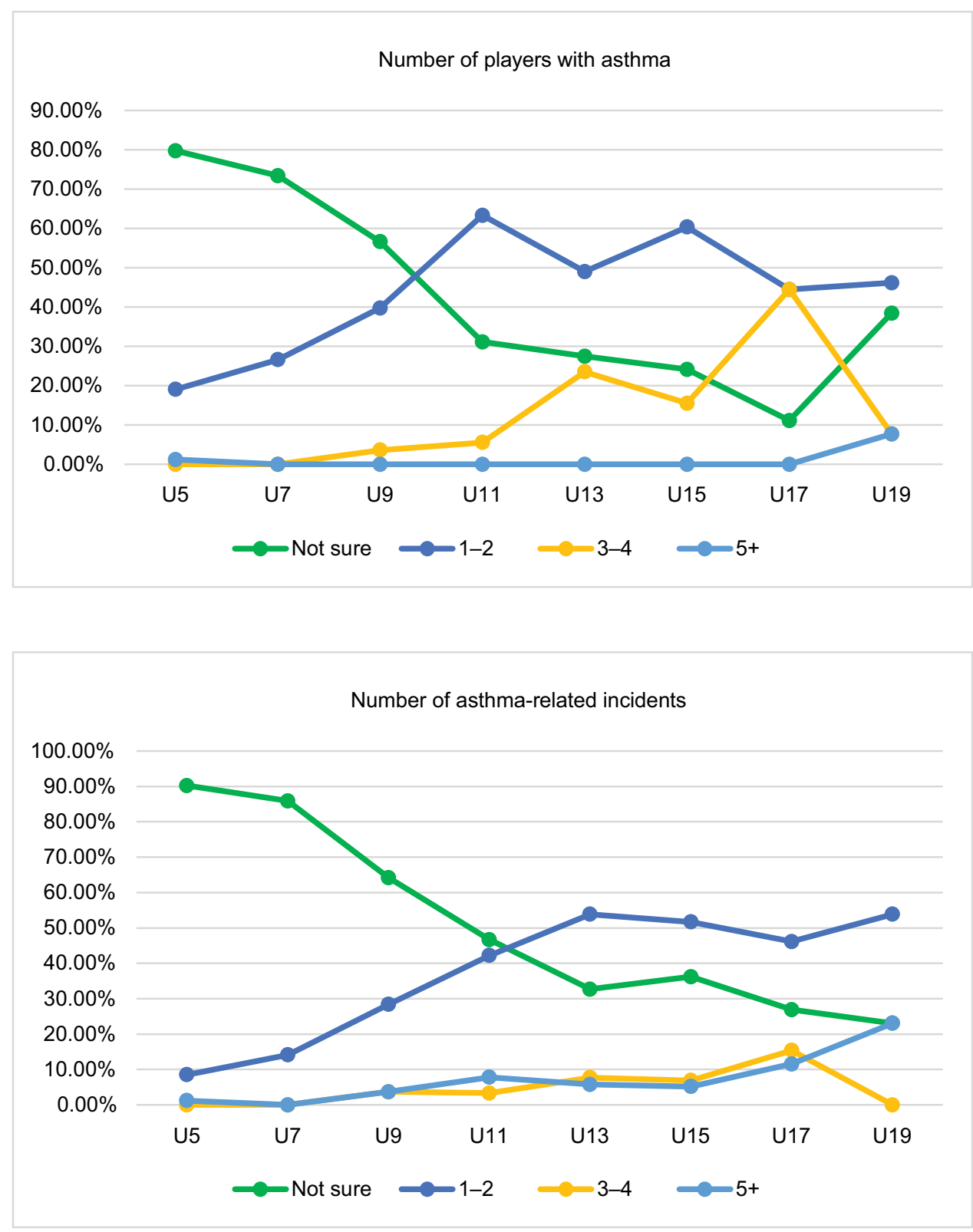

Figure 4 Responses to number of players with asthma (top) and number of asthma-related incidents (bottom) filtered by age level coached.

indicate that they felt training in asthma management should be mandatory. No significant differences were noted in regard to the other questions.

We then filtered the responses to these barrier questions by the level of asthma experience that these coaches had based on their responses to whether they or their child had asthma and the number of asthma-related incidents that they had encountered. Regardless of whether they or their child had asthma, coaches felt equally that incorporation of training would be beneficial, training should be mandatory, and they would be interested in training were it to be developed.
It should be noted that respondents who answered "no" to whether they or their child had asthma were more likely than those who answered "yes" to disagree with the statement that youth coaches have adequate knowledge in asthma management. When answers to these questions were compared by number of asthma-related incidents encountered by coaches, there were no significant differences noted.

We also filtered the responses to these barriers-related questions by gender being coached, level of training received (EMSA or ASA), and by confidence levels, but there were no significant differences noted. 


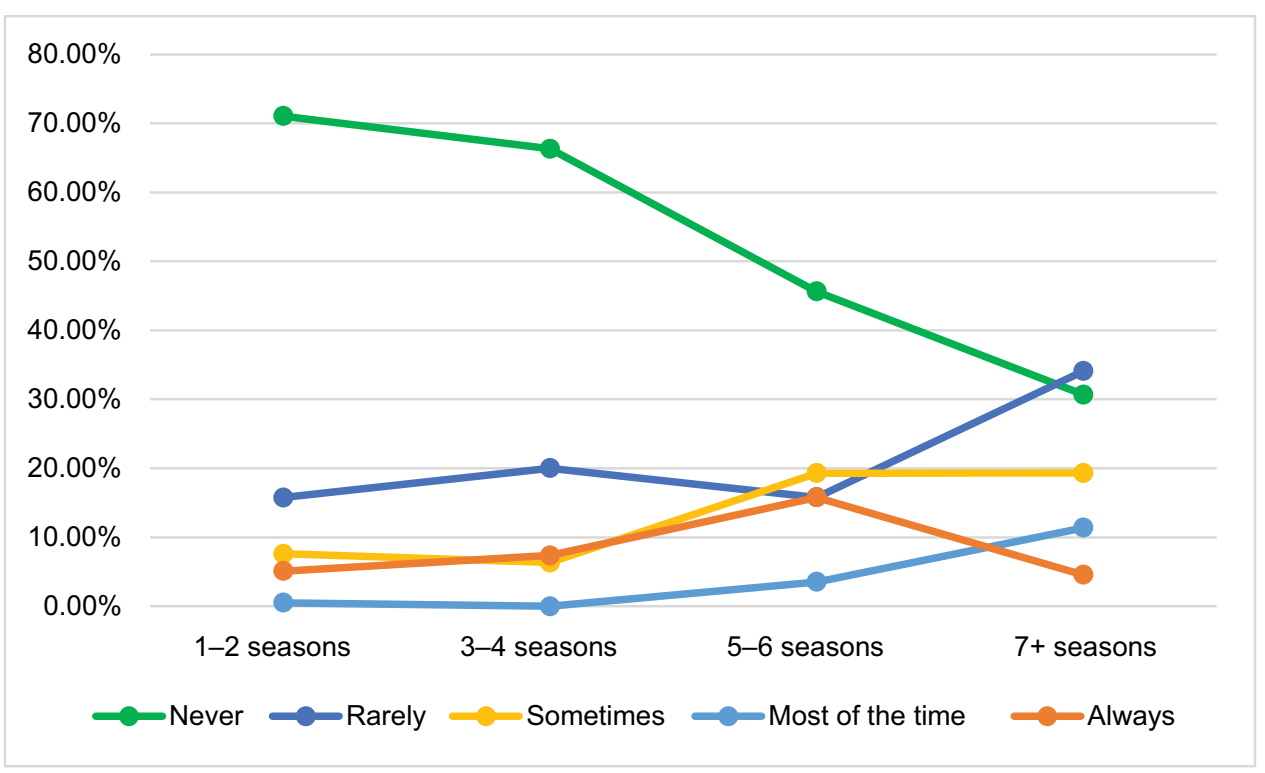

Figure 5 Responses to discussion of a plan to follow should a player suffer an asthma attack filtered by number of seasons coached.

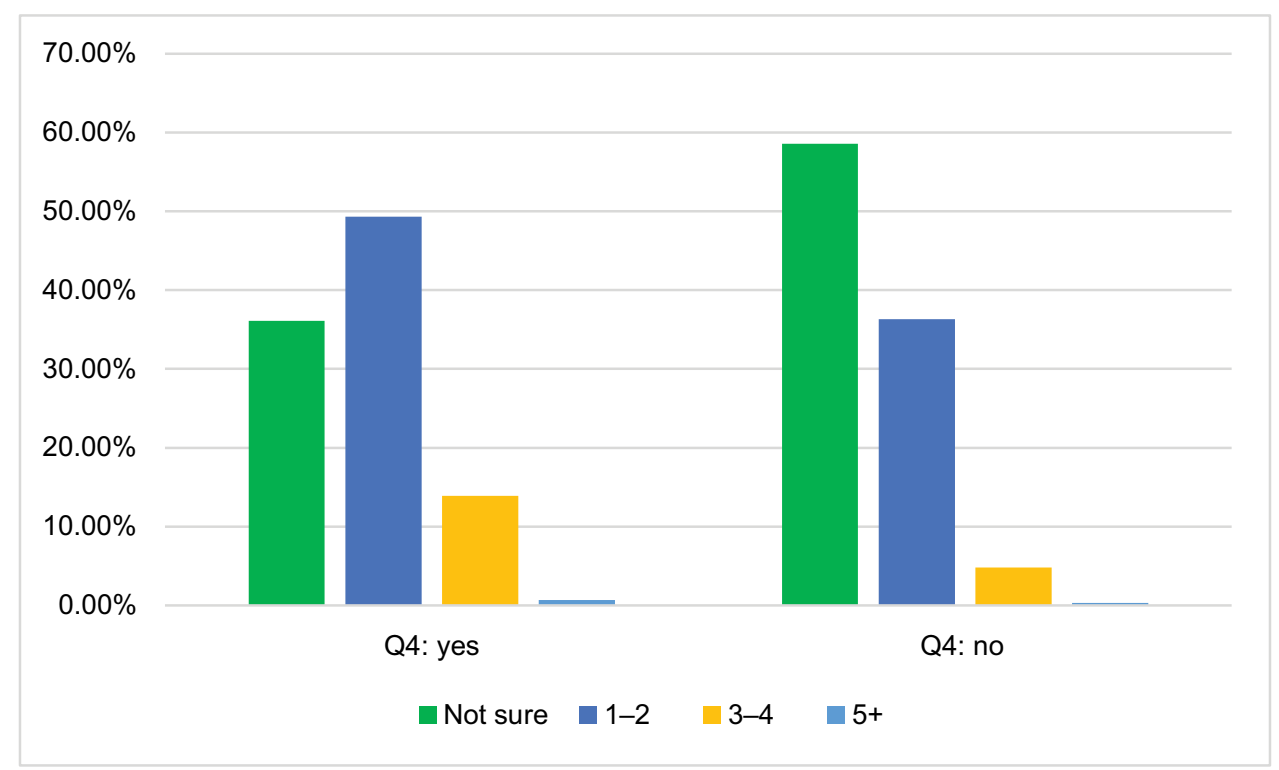

Figure 6 Responses to number of players with asthma filtered by whether they or their child has asthma.

\section{Discussion}

Athletes playing soccer are susceptible to asthma attacks, in some cases even leading to death, meaning that having coaches with appropriate asthma knowledge at games/practices would ease the tension of asthmatic players and their parents. ${ }^{10}$ This study is the first large-scale study assessing the knowledge of youth soccer coaches on asthma, whether there is a need for asthma-related training, and the barriers to administering asthma-related training to coaches. It should be noted that the majority of the respondents were inexperienced coaches, coached younger age groups, and out of the coaches who completed the questionnaire, close to one-third of the respondents indicated that either themselves or their child had asthma. This could be an indication of bias in our sample of coaches, which should be considered when interpreting these results.

Coaches knowledge regarding attack prevention is mixed, but most coaches know how to treat an asthma attack and 


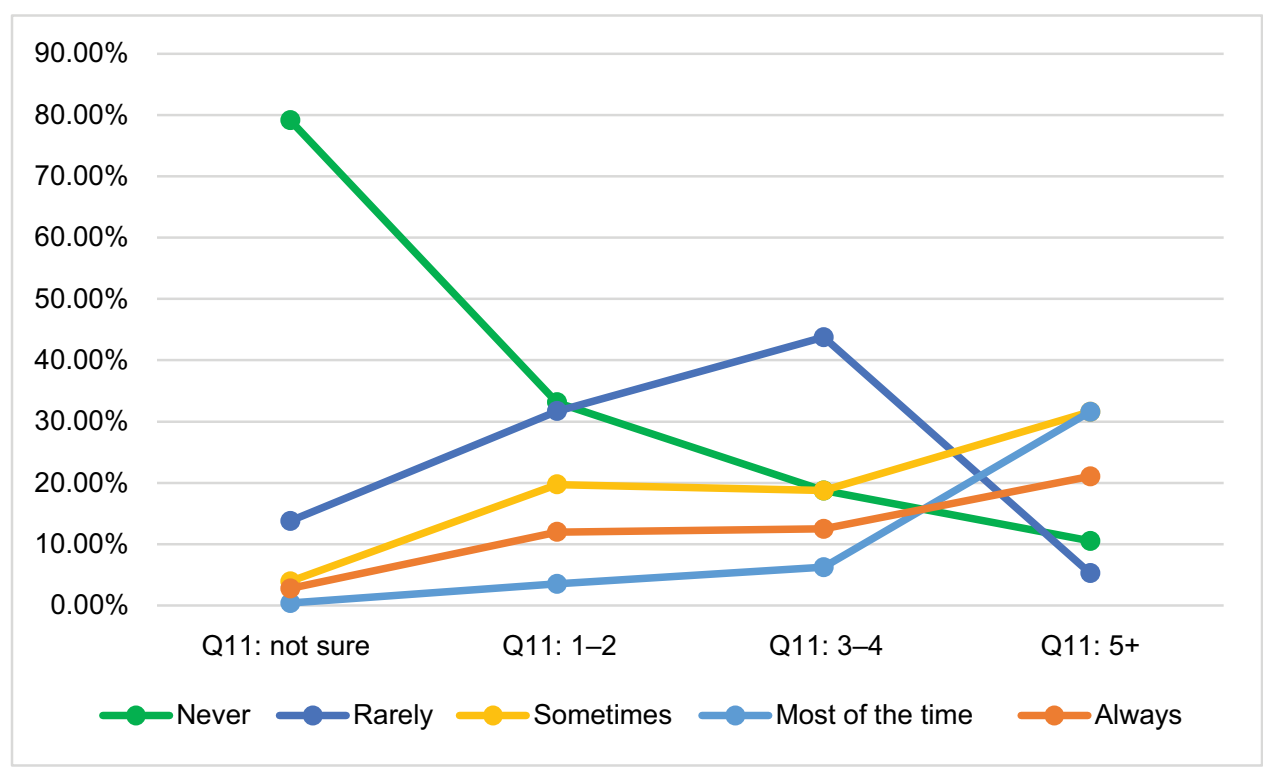

Figure 7 Responses to discussion of a plan to follow should a player suffer an asthma attack filtered by number of asthma-related incidents.

Table 6 Barriers to administration of training

\begin{tabular}{|c|c|c|c|}
\hline Questions & Levels & No. of subjects & $\%$ of subjects \\
\hline $\begin{array}{l}\text { Do you think incorporation of asthma } \\
\text { management protocol into coach training } \\
\text { would be beneficial? }\end{array}$ & $\begin{array}{l}\text { Yes } \\
\text { No }\end{array}$ & $\begin{array}{l}399 \\
39\end{array}$ & $\begin{array}{l}91.10 \\
8.90\end{array}$ \\
\hline $\begin{array}{l}\text { What would be the best way to } \\
\text { incorporate asthma-related protocol into } \\
\text { coach training? }\end{array}$ & $\begin{array}{l}\text { Pocket guide } \\
\text { Online module } \\
\text { Short segment into current EMSA training } \\
\text { Separate I hour asthma training course }\end{array}$ & $\begin{array}{l}184 \\
83 \\
154 \\
17\end{array}$ & $\begin{array}{l}42.01 \\
18.95 \\
35.16 \\
3.88\end{array}$ \\
\hline $\begin{array}{l}\text { Should training in asthma management be } \\
\text { mandatory for all EMSA coaches? }\end{array}$ & $\begin{array}{l}\text { Yes } \\
\text { No }\end{array}$ & $\begin{array}{l}301 \\
136\end{array}$ & $\begin{array}{l}68.88 \\
31.12\end{array}$ \\
\hline $\begin{array}{l}\text { Would you be interested in asthma } \\
\text { training if it were to be developed by } \\
\text { EMSA? }\end{array}$ & $\begin{array}{l}\text { Yes } \\
\text { No }\end{array}$ & $\begin{array}{l}374 \\
65\end{array}$ & $\begin{array}{l}85.19 \\
14.81\end{array}$ \\
\hline $\begin{array}{l}\text { Asthma is adequately covered in current } \\
\text { coaching courses. }\end{array}$ & $\begin{array}{l}\text { Strongly disagree } \\
\text { Disagree } \\
\text { Agree } \\
\text { Strongly agree }\end{array}$ & $\begin{array}{l}73 \\
295 \\
58 \\
2\end{array}$ & $\begin{array}{l}17.06 \\
68.93 \\
13.55 \\
0.47\end{array}$ \\
\hline Asthma does not affect many children. & $\begin{array}{l}\text { Strongly disagree } \\
\text { Disagree } \\
\text { Agree } \\
\text { Strongly agree } \\
\end{array}$ & $\begin{array}{l}78 \\
279 \\
76 \\
5\end{array}$ & $\begin{array}{l}17.81 \\
63.70 \\
17.35 \\
1.14 \\
\end{array}$ \\
\hline $\begin{array}{l}\text { Asthma is already appropriately managed } \\
\text { by parents and physicians. }\end{array}$ & $\begin{array}{l}\text { Strongly disagree } \\
\text { Disagree } \\
\text { Agree } \\
\text { Strongly agree }\end{array}$ & $\begin{array}{l}14 \\
138 \\
273 \\
12\end{array}$ & $\begin{array}{l}3.20 \\
31.59 \\
62.47 \\
2.75\end{array}$ \\
\hline $\begin{array}{l}\text { Youth soccer coaches have adequate } \\
\text { knowledge in asthma management. }\end{array}$ & $\begin{array}{l}\text { Strongly disagree } \\
\text { Disagree } \\
\text { Agree } \\
\text { Strongly agree }\end{array}$ & $\begin{array}{l}52 \\
315 \\
68 \\
0\end{array}$ & $\begin{array}{l}11.95 \\
72.41 \\
15.63 \\
0.00\end{array}$ \\
\hline
\end{tabular}

Abbreviation: EMSA, Edmonton Minor Soccer Association.

are able to appropriately handle a situation where an asthmatic player seems out of breath. It is important to note that many of the respondents had not received any form of coach training. However, even among those participants who had received some form of coach training, the majority of these coaches did not receive any asthma-related training at these 


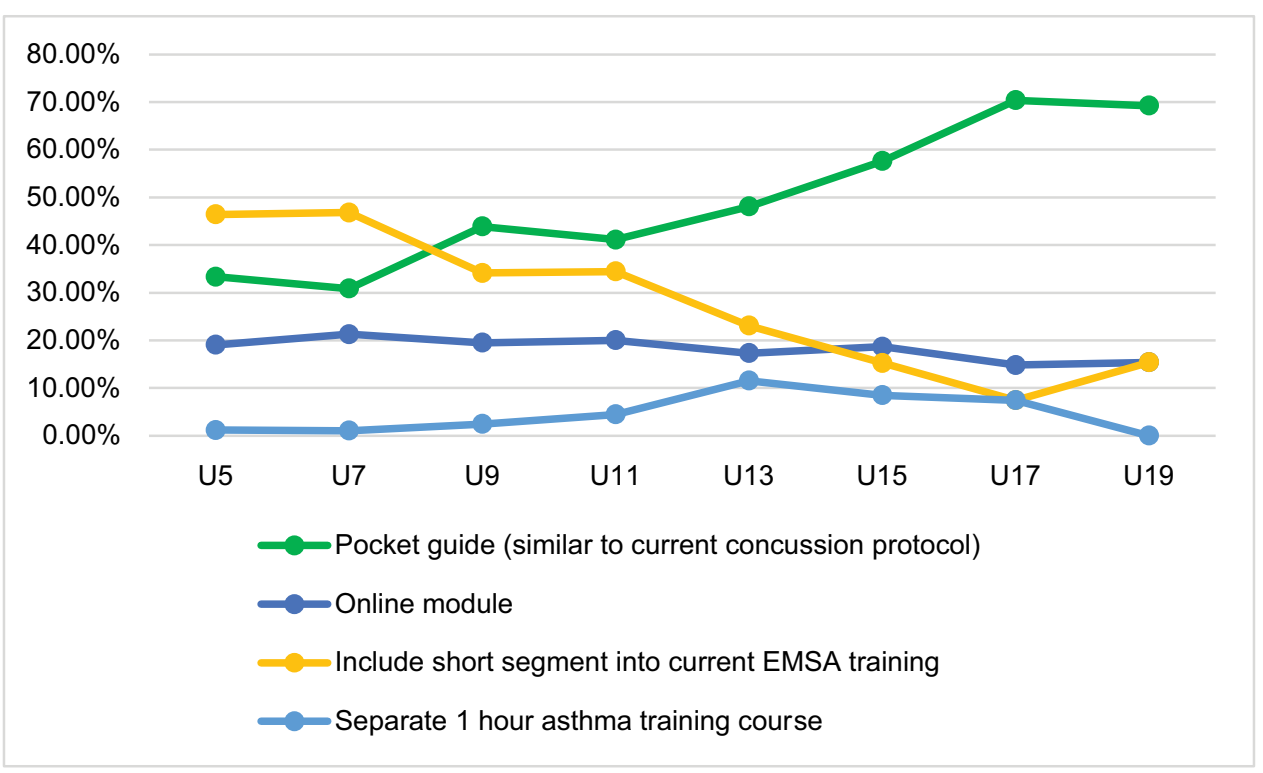

Figure 8 Responses to the best method to administer asthma management training filtered by age level coached. Abbreviation: EMSA, Edmonton Minor Soccer Association.

sessions. Despite the poor coverage of asthma-related topics in current coaching courses, the results indicate that there are certain areas on which coaches already possess adequate knowledge. Therefore, future coaching courses should be developed regarding asthma attack prevention rather than treatment of asthma attacks.

Coaches at higher age levels and with more experience possess greater knowledge in terms of asthma attack prevention compared to their colleagues at lower age levels and with less experience. Coaches could be learning how to manage asthma through their experience as coaches. Since there is a relationship between level of experience and age level being coached, it is likely that coaches with more experience tend to coach at older age levels. However, a worrying trend is that coaches at younger age groups, particularly U5 and U7, tend to have quite poor knowledge regarding how to prevent an asthma attack. This issue is confounded by the fact that during early childhood, parents and other caregivers, not the child, bare the primary responsibility for asthma management. ${ }^{16}$ If left unattended, younger children could be unable to appropriately address their own asthmatic symptoms, meaning that it could be beneficial if coaches were able to recognize and manage symptoms at least at a preliminary level in these younger children.

In terms of asthma attack prevention in relation to soccer, it is important to note that although providing an inhaler before games/practices is the best way to prevent an attack, literature on the topic also suggests that appropriate warmup exercises can reduce the incidence of exercise-induced asthma for children in asthmogenic sports, including soccer. ${ }^{17,18}$ Warm-up exercises include short, repeated warm-ups, and warm-ups provided at submaximal intensity, both of which were significant in reducing both the occurrence and severity of bronchoconstriction during sport.

Most coaches were unsure how many players on their team had asthma and also unsure of how many asthma-related incidents they had encountered as a coach. This would make sense given that the majority of coaches are not trained medical professionals and rather just volunteers, so it should not be assumed that they can readily assess asthmatic situations given that they lacked the appropriate training to do so. The need for asthma-related training is most pronounced when considering that a clear majority of coaches "never" or "rarely" discussed an asthma emergency action plan should a player have an asthma attack. This result is troublesome because it flows from this that the majority of coaches given an emergency situation with an asthmatic player would be illprepared to cope with the situation. This issue is confounded by the fact that there are many parents who are "non-attender parents," meaning that they drop their child off at practices and games but do not stay to watch. ${ }^{19}$ Although the parents of asthmatics do tend to show greater levels of care and concern for their children's health status, there is still the possibility for asthmatic children to be left alone in the care 
of coaches at games and practices. ${ }^{20}$ Furthermore, instances of EIB can occur in up to $10 \%$ of people without any previous asthma diagnosis. ${ }^{4,5}$ This implies a need for coaches to take some time early in the season to discuss with all parents of children on their team what they would do should a child have an asthma attack. In addition to this, it would also be appropriate for coaches to deal with asthmatic players on a one to one basis, so they can be made aware of what they should do if an asthmatic situation were to arise.

The results indicated that there would be few barriers to administration of asthma-related training to coaches, which was inconsistent with our third hypothesis. An overwhelming majority of respondents indicated that 1) they disagreed that youth soccer coaches have adequate knowledge in asthma management, 2) they felt asthma-related training should be made mandatory for all EMSA coaches, 3) they disagreed that asthma is adequately covered in current coaching courses, 4) incorporation of asthma management protocol into coach training would be beneficial, and 5) they would be interested in asthma training were it to be developed by EMSA. Cumulatively, these responses indicate that there would be minimal backlash or nonparticipation if the appropriate asthma-related training was developed. Additionally, coaches showed "positive" attitudes toward asthma, as only a minority of respondents agreed that asthma does not affect many children. It is important to note, however, that a majority of coaches did feel that asthma is already appropriately managed by parents and physicians. When considering these responses together, it can be said that although coaches feel that parents and physicians should bare the primary responsibility for asthma management, coaches should possess the knowledge necessary to care for an asthmatic child as it pertains to their role as coaches.

The best way to administer asthma-related training was also investigated as part of this study and the results indicated that respondents wanted either a "Pocket Guide" or inclusion of a "short segment into current EMSA training." A pocket guide would imply the least amount of effort on behalf of the coaches, since they would not need to pay for or attend any additional training. Coaches with less experience seemed to be more split between the two choices, whereas experienced coaches were more clearly in favor of a pocket guide. This can be interpreted as either experienced coaches lacking the desire to attend additional training courses or their intuition that a "pocket guide" may have the greatest receptiveness among coaches. Further to this, the most experienced coaches had the greatest percentage of respondents who had felt that training in asthma protocol should be mandatory. An overwhelming support from the experienced coaches for asthma training is significant and reassuring.

It has been noted that despite asthmatic children taking part in less physical activity or activity that is mild and moderate, there is no significant difference between the positive attitudes of asthmatic children and their non-asthmatic peers toward exercise. $^{21}$

To ensure that asthmatic children and their parents feel comfortable in taking part in organized sports such as soccer, it would be appropriate to have coaches with an adequate knowledge of 1) how to recognize asthmatic symptoms, 2) the steps to prevent an asthma attack, and 3) how to treat or assist a player who may be having an asthma attack. The results of this study are comparable with previous work looking at the knowledge of youth soccer coaches and managers, which found that coaches had minimal knowledge regarding asthma attack treatment and prevention. ${ }^{14}$ However, the sample of coaches we surveyed appeared to have greater knowledge in the treatment of asthma attacks, less knowledge in the prevention of asthma attacks, and greater confidence levels on average when compared to previous work on this topic. A previous study looking at the perception and knowledge about asthma of coaches ranging in different sports from middle school to collegiate levels similarly called for specific educational interventions aimed at increasing their asthma awareness and knowledge. ${ }^{22}$ Previous literature that has focused on athletic trainers' knowledge of asthma conditions stated that trainers are in a position where they can recognize irregular breathing symptoms in athletes with both diagnosed and undiagnosed asthma. ${ }^{23,24}$ Similar to how athletic trainers can be on the front lines of recognizing breathing difficulties in athletes, soccer coaches could also aid in the recognition, diagnosis, and management of asthma after receiving appropriate training.

This study does have limitations, including issues inherent to survey-based research, such as response bias and low response rates. Respondents may choose to provide answers that they feel are the most socially desirable, which may lead to an overestimation or underestimation of coaches' confidence and knowledge in dealing with asthma. Additionally, participant responses may be limited by the closed-ended questions used in the survey. Despite sending out the survey to 2,300 coaches, only 513 coaches filled out the survey. This low response rate was anticipated, since the coaches are volunteers. Furthermore, our survey instrument was not fully validated by previous research, with many of the ques- 
tions being based on clinical and coaching experience of the researchers and EMSA collaborators. Future studies looking to investigate this topic should utilize a validated survey instrument, aim to survey a larger population of interest, and could attempt to administer open-ended questions or interview participants.

Based on our results, since there is currently no specific asthma education protocol in place for soccer coaches, developing and testing the efficacy of an asthma education program would be the logical next step. This study focused specifically on the knowledge of soccer coaches' who are part of the EMSA, so it would be beneficial if future studies could look to the knowledge of coaches in other sports, such as swimming or ice hockey. Similarly, it would be appropriate to study if the knowledge of coaches regarding asthma is similar around the world or if it is limited to particular geographic regions, where soccer may be more or less popular. Additionally, there has been limited research on the topic with only one other study looking specifically at soccer coaches' asthma knowledge, so, future larger scale studies are warranted.

\section{Conclusion}

The results of this study indicate that soccer coaches have limited knowledge in regard to asthma management, acknowledge a need for asthma-related training, and are willing to participate in and could benefit from educational interventions as it pertains to their roles as coaches.

\section{Acknowledgments}

We would like to thank the Edmonton Minor Soccer Association (EMSA), specifically Mr Dragos Niculescu and $\mathrm{Mr}$ Mario Charpentier, for collaborating with us on this study. We would also like to thank the University of Alberta, Department of Family Medicine for funding this project.

\section{Author contributions}

CS conceived the idea of the study, performed the literature review, was involved in the design of the study and development of the survey, conducted the analysis, and drafted the manuscript. AC was involved with the study development and design at all stages and reviewed and edited the manuscript. All authors contributed to data analysis, drafting or revising the article, gave final approval of the version to be published, and agree to be accountable for all aspects of the work.

\section{Disclosure}

The authors report no conflicts of interest in this work.

\section{References}

1. Maslan J, Mims JW. What is asthma? Pathophysiology, demographics, and health care costs. Otolaryngol Clin North Am. 2014;47(1):13-22.

2. Kudo M, Ishigatsubo Y, Aoki I. Pathology of asthma. Front Microbiol. 2013;4:263.

3. Asher I, Pearce N. Global burden of asthma among children. Int J Tuberc Lung Dis. 2014;18(11):1269-1278.

4. Parsons JP, Mastronarde JG. Exercise-induced bronchoconstriction in athletes. Chest. 2005;128(6):3966-3974.

5. Del Giacco SR, Firinu D, Bjermer L, Carlsen KH. Exercise and asthma: an overview. Eur Clin Respir J. 2015;2:27984.

6. Choi IS, Ki WJ, Kim TO, Han ER, Seo IK. Seasonal factors influencing exercise-induced asthma. Allergy Asthma Immunol Res. 2012;4(4):192-198.

7. Glazebrook C, McPherson AC, Macdonald IA, et al. Asthma as a barrier to children's physical activity: implications for body mass index and mental health. Pediatrics. 2006;118(6):2443-2449.

8. van Gent R, van Essen-Zandvliet EE, Klijn P, Brackel HJ, Kimpen JL, van der Ent CK. Participation in daily life of children with asthma. J Asthma. 2008;45(9):807-813.

9. Lochte L, Nielsen KG, Petersen PE, Platts-Mills TAE. Childhood asthma and physical activity: a systematic review with meta-analysis and Graphic Appraisal Tool for Epidemiology assessment. BMC Pediatr. 2016;16:50

10. Becker JM, Rogers J, Rossini G, Mirchandani H, D’Alonzo GE Jr. Asthma deaths during sports: report of a 7-year experience. J Allergy Clin Immunol. 2004;113(2):264-267.

11. Stølen T, Chamari K, Castagna C, Wisløff U. Physiology of soccer. Sports Medicine. 2005;35(6):501-536.

12. Khajotia R. Exercise-induced asthma: fresh insights and an overview. Malays Fam Physician. 2008;3(1):21-24.

13. Cardwell FS, Elliott SJ. Investigating youth sport coach perspectives of an asthma education module. J Environ Public Health. 2018;2018:2512010.

14. Pnina W, Bazzy-Asaad A, Tolomeo C. Lack of identification of asthmatic players in a youth soccer league. JAsthma Allergy Educ. 2010;1:117-121.

15. SurveyMonkey: The World's Most Popular Free Online Survey Tool [homepage on the Internet]. 2018. Available from: https://www.surveymonkey.com/. Accessed May 1, 2018.

16. Searle A, Jago R, Henderson J. Children's, parents' and health professionals' views on the management of childhood asthma: a qualitative study. NPJ Prim Care Respir Med. 2017;27(1):53.

17. de Bisschop C, Guenard H, Desnot P, Vergeret J. Reduction of exerciseinduced asthma in children by short, repeated warm ups. Br J Sports Med. 1999;33(2):100-104.

18. Mtshali BF, Mokwena K, Oguntibeju OO. Effect of submaximal warmup exercise on exercise-induced asthma in African school children. West Indian Med J. 2015;64(2):117-125.

19. Kirk D, Macphail A. Social positioning and the construction of a youth sports club. Int Rev Sociol Sport. 2003;38(1):23-44.

20. Borhani F, Asadi N, Mohsenpour M. The experiences of mothers with asthmatic children: a content analysis. J Caring Sci. 2012;1(3):115-121.

21. Dimitrakaki V, Porpodis K, Bebetsos E, et al. Attitudes of asthmatic and nonasthmatic children to physical exercise. Patient Prefer Adherence. 2013;7:81-88

22. Therkorn JH, Shendell DG. Evaluation and characterization of environmental risks and asthma management knowledge and awareness through surveys of coaches, athlete parents/guardians, and athletes. J Asthma Allergy Educ. 2012;3(3):106-116.

23. Miller MG, Weiler JM, Baker R, Collins J, D’Alonzo G. National Athletic Trainers' Association position statement: management of asthma in athletes. J Athl Train. 2005;40(3):224-245.

24. Labella CR, Sanders DB, Sullivan C. Athletic trainers' experience and comfort with evaluation and management of asthma: a pilot study. J Asthma. 2009;46(1):16-20.

25. Welcome to EMSA [homepage on the Internet]. 2018. Available from: https://emsamain.com/. Accessed May 1, 2018. 
The Open Access Journal of Sports Medicine is an international, peer-reviewed, open access journal publishing original research, reports, reviews and commentaries on all areas of sports medicine. The journal is included on PubMed. The manuscript management system is completely online and includes a very quick and fair peer-review system. Visit http://www.dovepress.com/testimonials.php to read real quotes from published authors.

Submit your manuscript here: http://www.dovepress.com/open-access-journal-of-sports-medicine-journal 